EXTENDED REPORT

\title{
Human retinal microglia express candidate receptors for HIV-1 infection
}

\author{
V T Pham, L Wen, P McCluskey, M C Madigan, P L Penfold
}

Br J Ophthalmol 2005;89:753-757. doi: 10.1136/bjo.2004.057828

See end of article for authors' affiliations

.....................

Correspondence to:

Dr Michele C Madigan,

Save Sight Institute, GPO

Box 4337, Sydney NSW

2001 Australia; michele@

eye.usyd.edu.au

Accepted for publication

9 October 2004

\begin{abstract}
Background/aims: Microglia are the primary antigen presenting cells in the central nervous system and the retina, and can harbour viral antigens that may damage neural tissue via the release of neurotoxins. All cells bearing CD4 molecules and co-receptors (members of the chemokine receptor and Fc $\gamma$ receptor families) are potential targets for the human immunodeficiency virus (HIV). In this study, retinal microglia (in vitro and in situ) were investigated for the expression of candidate HIV-1 binding receptors.

Methods: Cultured human retinal microglia and frozen sections of human retinas were used. Immunohistochemistry was used to investigate expression of cell surface receptors necessary for HIV-1 infection: CD4, CC chemokine receptor 5 (CCR5), and Fc $\gamma$ receptors.

Results: Human retinal microglia expressed detectable levels of CD4, CD16, CD64, and CCR5 in vitro and Fc $\gamma$ receptor I (CD64) in situ.

Conclusions: Human retinal microglia express several candidate receptors required for viral binding and as such may be a potential reservoir for HIV-1 infection.
\end{abstract}

$M$ icroglia constitute a distinct cell population within the central nervous system (CNS) including the retina, and are involved in several physiological ${ }^{1}$ as well as pathological processes. ${ }^{2}$ The phenotype of microglia has been demonstrated to be consistent with that of myeloid cells. ${ }^{34}$ During acquired immunodeficiency syndrome (AIDS), microglial cells are infected by human immunodeficiency virus-1 (HIV-1), contributing to neuronal damage and blood-brain barrier (BBB) breakdown through their activation and eventual secretion of potential neurotoxins. ${ }^{5}{ }^{6}$ In vitro studies have demonstrated that microglia can be directly infected. ${ }^{7}$ In vivo, HIV-l can infect endothelial cells and gain access to the brain tissue across the $\mathrm{BBB}^{8}$ Moreover, HIV-l can be "hidden" in blood borne monocytic cells and carried into the brain tissue during the turnover of monocytes with the local microglial cells, evading immune surveillance in accordance with the "Trojan horse" theory."

Clinical studies have shown that HIV-1 infected individuals can suffer visual field disturbances, ${ }^{10}$ impairments in colour vision, ${ }^{11}$ and opportunistic retinitis. ${ }^{12}$ The underlying pathogenesis of these ocular changes, including the involvement of retinal microglia, remains to be determined; however, retinal glial cells, including microglia, have been reported as candidates for HIV-l infection, ${ }^{13}$ and viral particles have been found within human retinas. ${ }^{14}$

Several pro-inflammatory cytokines such as tumour necrosis factor alpha (TNF- $\alpha$ ), interleukins IL-1, and IL-6 have been demonstrated in HIV-1 infected retina, ${ }^{15}$ perhaps derived from activated microglia, an important source of proinflammatory cytokines in other neural tissues. ${ }^{16}{ }^{17}$ The release of pro-inflammatory cytokines has also been implicated in the induction of ganglion cell $\operatorname{loss}^{18}$ and breakdown of the blood-retinal barrier (BRB). ${ }^{19}$ The latter can contribute to the pathogenesis of cystoid macular oedema ${ }^{20}$ and could eventually provide access to opportunistic infectious agents such as cytomegalovirus (CMV) that are commonly seen in HIV-l patients. ${ }^{21}$

The potential infectivity of retinal microglia by HIV-1 remains to be confirmed. In vivo viral antigen immunoreactivity has not been conclusively shown, and ultrastructural studies have been unable to convincingly demonstrate
HIV-1 infected retinal microglial cells. In this study, we investigated cultured and in situ human retinal microglia for the expression of surface receptors considered important for cellular entry of HIV-1.

\section{MATERIALS AND METHODS}

Microglial culture

For tissue culture, adult human eyes from donors aged 1039 years $(n=7)$, with 17 (SD 5.5) hours postmortem delay and free from detectable ocular history, were obtained from the Lions NSW Eye Bank and with approval from the human ethics committee, University of Sydney. All studies conformed to the tenets of the Declaration of Helsinki.

Human retinal microglia were cultured as described previously. ${ }^{22}$ Briefly, the retina was dissected from the choroid and the retinal pigmented epithelium (RPE), then incubated in $0.05 \%$ trypsin $/ 0.02 \%$ EDTA (ThermoElectron Pty Ltd, Australia) and $150 \mu \mathrm{l}$ of DNase (Roche Applied Sciences Australia Pty Ltd) for 10 minutes at $37^{\circ} \mathrm{C}$. Digests were doubled filtered through $70 \mu \mathrm{m}$ and $44 \mu \mathrm{m}$ meshes, centrifuged, and the cells resuspended in growth medium (Iscoves Modification of Dubecco's medium, IMDM, ThermoElectron) supplemented with $10 \%$ FBS, $50 \mathrm{IU} / \mathrm{ml}$ penicillin, $50 \mu \mathrm{g} / \mathrm{ml}$ streptomycin, and $2 \mathrm{mM}$ glutamine, and cultured in a humidified atmosphere of $5 \% \mathrm{CO}_{2}$ and air at $37^{\circ} \mathrm{C}$. After 7 days, cultures were washed with HBSS and fresh growth medium was added and cells were cultured for a further 7 days. The supernatant containing predominantly microglia $^{22}$ was centrifuged at $400 \times g$ for 7 minutes at room temperature (RT). The pellet was then resuspended in growth medium, and cells seeded on plastic and glass coverslips for immunostaining experiments.

Abbreviations: AIDS, acquired immunodeficiency syndrome; BBB, blood-brain barrier; BRB, blood-retinal barrier; CCR5, CC chemokine receptor 5; CMV, cyłomegalovirus; HIV, human immunodeficiency virus; IL, interleukin; INL, inner nuclear layer; IPL, inner plexiform layer; PBS, phosphate buffered saline; RPE, retinal pigmented epithelium; TNF- $\alpha$, tumour necrosis factor alpha 
Immunohistochemistry: fluorescence

After 3-5 days in culture, coverslips were fixed in 2\% paraformaldehyde, and subsequently rinsed in $0.1 \mathrm{M}$ phosphate buffered saline (PBS). Following incubation in 10\% normal sheep serum (NSS) for 15 minutes to reduce nonspecific antibody binding, cells were immunolabelled with primary mouse monoclonal antibodies to CD4 (Neomarkers, 1:50), CD16, CD32, CD64, CD45, and CCR5 (BectonDickinson Pty Ltd, 1:50) for 1 hour at RT. After rinsing in PBS, coverslips were incubated in biotinylated sheep antimouse immunoglobulins (Amersham Pharmacia Biotech Pty Ltd, 1:100) for 1 hour, further rinsed in PBS, and incubated in streptavidin-Cy3 (Zymed Inc, San Francisco, CA, USA) ( $1: 200)$ for 45 minutes, followed by three washes in PBS. All antibodies were diluted in PBS and 2\% NSS. Immunolabelled coverslips were mounted onto glass slides with glycerol.

\section{Immunohistochemistry: immunoperoxidase}

After blocking in 10\% NSS and incubating in primary and biotinylated secondary antibodies, coverslips were incubated in ExtrAvidin peroxidase (Sigma Pty Ltd) (1:200 in PBS) for 1 hour and antibody binding visualised with 3-3' diaminobenzidine (DAB) (Sigma). Coverslips were rinsed several times in PBS, counterstained in haematoxylin for 23 minutes and dehydrated through alcohols and xylene and mounted in DePeX.

\section{Human retinal sections}

Adult human eyes from donors aged $35-70$ years $(n=7)$, less than 24 hours postmortem delay and free from detectable ocular history, were obtained with consent from the Lions NSW Eye Bank and approval from the human ethics committee, University of Sydney. The anterior segments and vitreous were removed and the eye cups fixed in $2 \%$ paraformaldehyde/PBS for more than 24 hours. Retinal trephines (6 mm diameter), centred approximately $3 \mathrm{~mm}$ from the papillomacular region, were taken from fixed eye cups. Retinas were detached in PBS and residual vitreous gently removed from the retinal surface with sponge and scissors, followed by several rinses in PBS. Specimens were then incubated in a $30 \%$ sucrose/PBS solution for 1 hour at RT. Following this, the tissues were embedded in TissueTek (Sakura Finetek, USA), frozen in liquid nitrogen cooled isopentane and $15 \mu \mathrm{m}$ sections cut using a Leitz Cryostat. The sections were collected on polylysine and gelatin coated glass slides and kept at $-20^{\circ} \mathrm{C}$ until used.

\section{Immunohistochemistry}

After rinsing in several changes of PBS for 15 minutes, sections were incubated in $10 \%$ NSS for 30 minutes at RT to reduce non-specific binding. Primary antibodies were then applied as above, and after an overnight incubation at $4^{\circ} \mathrm{C}$, slides were rinsed three times in PBS over 15 minutes. Localisation of the primary antibodies was detected using a biotinylated secondary anti-mouse antibody, ExtrAvidin peroxidase, and DAB as described above (immunocytochemistry: peroxidase). The slides were washed, counterstained with haematoxylin, dehydrated, coverslipped with DePeX and examined with light microscopy.

\section{RESULTS}

\section{Microglia in culture}

Within 3-5 days of seeding, three separate microglial cultures grew on coverslips. Cultured retinal microglia displayed an opalescent colour and veiled cell morphology, and remained adherent to the coverslips, helping to isolate them from the mixed retinal glial cells. All immunolabelling experiments were done after 14 days' culture, yielding increased numbers of resting microglial cells with typical ramified morphology.

\section{CD4 expression}

In culture, ramified retinal microglia expressed detectable levels of CD4 immunostaining. Immunoperoxidase positive granules were localised within the cell bodies while the cell processes stained weakly (fig $\mathrm{IB}$ and $\mathrm{C}$, table $\mathrm{I}$ ). IgG nonspecific isotype controls were negative (fig 1A, 2A) and CD45 immunolabelled positive controls showed strong staining of microglia (fig 1D, 2B). No obvious CD4 immunoreactivity was observed in any of the sections from human retinas (not shown).

\section{CCR5 expression}

Cultured retinal microglia expressed CCR5 receptors (fig 2C and D, table 1). Microglial cells with bipolar or ramified morphology were selected for microscopic examination. Bipolar ramified microglia displayed dense staining of the cell body but not the processes, in contrast with CD45 immunostaining where both cell bodies and processes were visible (fig 2B). Overall, fewer CCR5 positive cells were observed compared to CD45 positive cells in microglial culture. CCR5 immunoreactivity could not be detected in sections from human adult retinas (not shown).

\section{Fc $\gamma$ receptor expression}

In culture, retinal microglia expressed immunoreactivity for Fc $\gamma$ receptor III (CD16) (fig 2E) and Fc $\gamma$ receptor I (CD64) (fig 2F). Retinal sections from all specimens showed microglial cells immunostained for anti-Fc $\gamma$ receptor I (CD64) antibody (fig 3C). The CD64 immunoreactive cells displayed different morphologies depending on their location within the retinal layers, similar to the patterns of CD45 immunostaining of microglia (fig 3B). Microglial cells in the nerve fibre layer displayed an elongated shape, while microglial cells in the inner plexiform layer (IPL) and the inner nuclear layer (INL) had highly branched dendritiform morphology, although less ramified in the INL (fig 3C, table 1). Vessel associated microglia were CD45 and CD64 immunoreactive. IgG non-specific isotype controls were negative (fig 3A), and no obvious immunostaining was seen for antibodies to $F C \gamma$ receptors II or III (CD32 or CD16 respectively) (not shown).

\section{DISCUSSION}

Infection of monocytes/macrophages with HIV-1 occurs through direct interaction of the viral envelope glycoprotein gpl20 with the CD4 receptor. ${ }^{23}$ The lack of evidence confirming expression of this surface marker on certain cell types including microglia and astrocytes has prompted research into CD4 independent binding sites. Several earlier studies have suggested that viral infection may also occur

Table 1 Expression of immunoreactivity for viral binding receptors on cultured and in situ human retinal microglia

\begin{tabular}{|c|c|c|c|c|c|c|}
\hline & CD4 & CD16 (FcyRIII) & CD32 (FcyRII) & CD64 (FcyRI) & CD45 & CCR5 \\
\hline Cultured microglia & + & + & - & + & + & + \\
\hline In situ microglia & - & - & - & + & + & - \\
\hline
\end{tabular}



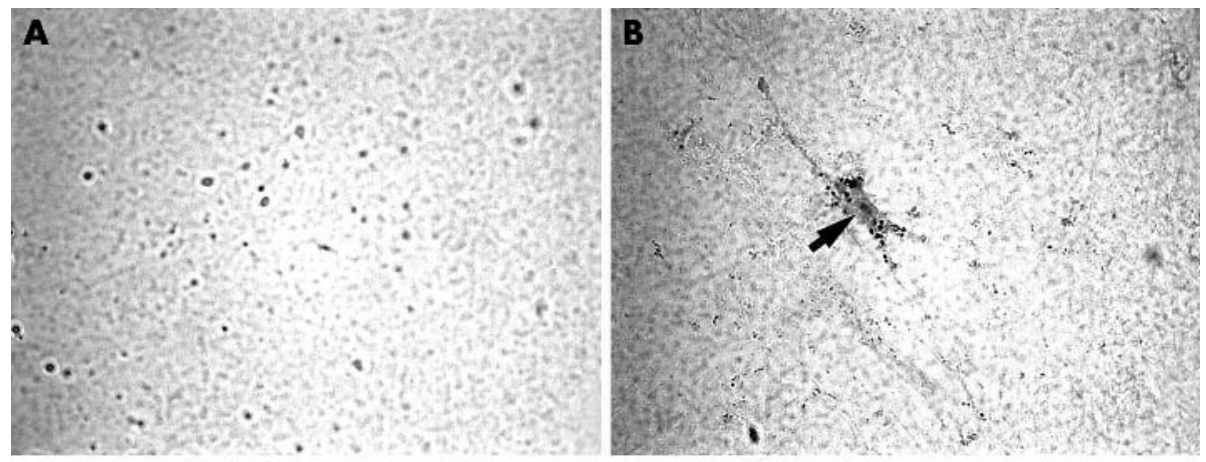

Figure 1 Immunoperoxidase staining of cultured human microglia. $(A) \lg G$ non-specific isotype control; ( $B$ and $C$ ) microglial cells (arrows) showing CD4 immunoreactivity; (D) a CD45 immunoreactive microglial cell (arrow). $(\times 50$.)
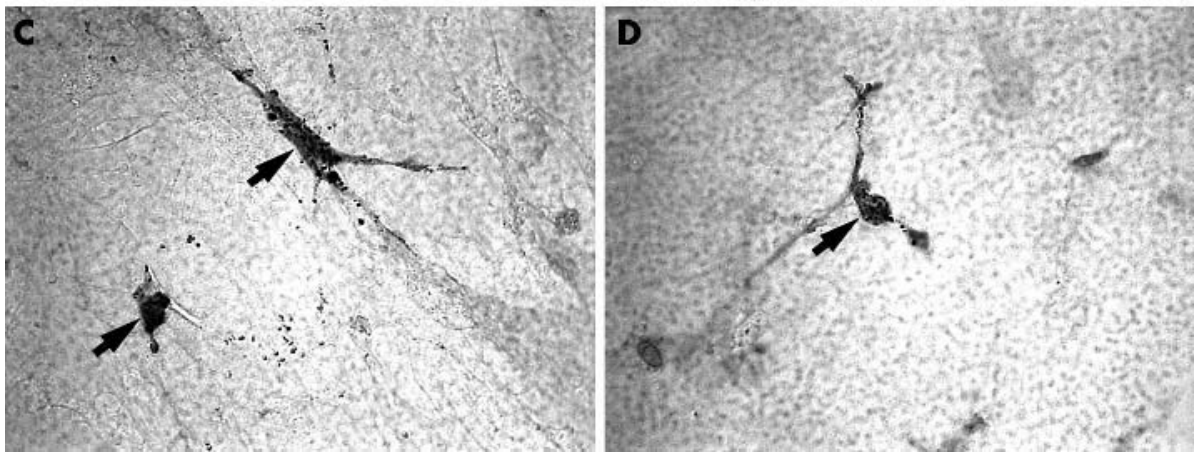

through the interaction of antibody opsonised HIV-1 with the Fc $\gamma$ Rs on mononuclear phagocyte series cells ${ }^{24}$ or through chemokine receptor molecules. ${ }^{25}$ More recently, the presence of CD4 has been shown to be essential for viral binding. ${ }^{26}$ Additionally, chemokine receptors-that is, CCR3, CXCR4, and CCR5, function as co-receptors necessary for viral internalisation ${ }^{26}$ and Fc $\gamma$ Rs enhance viral stability at the cell
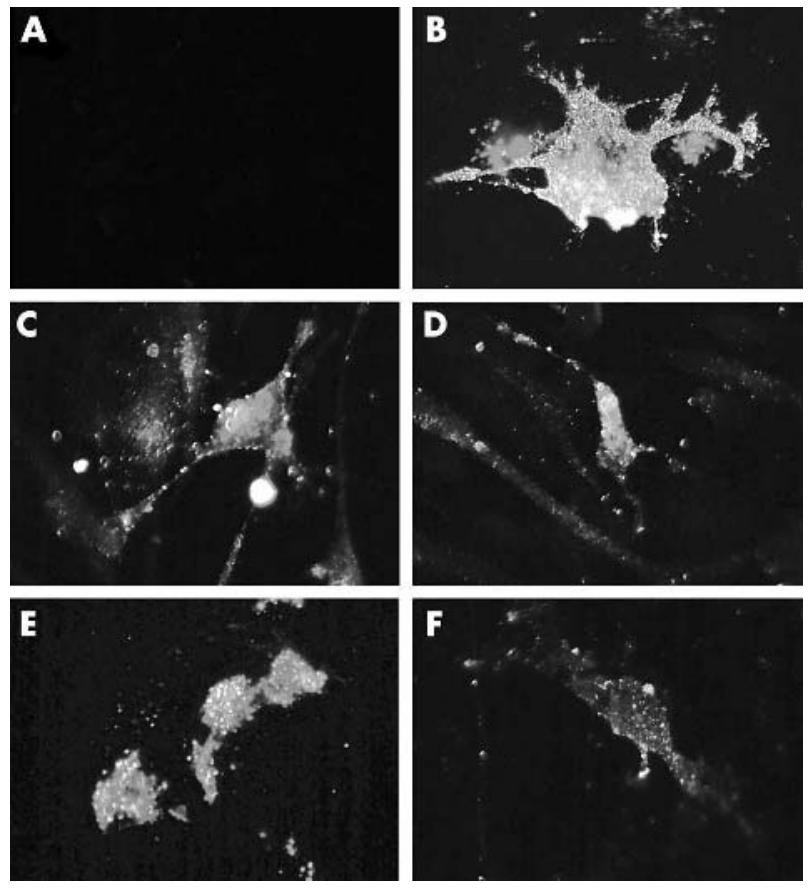

Figure 2 Immunofluorescence staining of cultured human microglia. (A) IgG non-specific isotype control; (B) a CD45 immunoreactive microglial cell; (C and D) microglial cells showing CCR5 immunoreactivity; (E) CD 16 immunoreactive microglial cells; (F) a CD64 immunoreactive microglial cell. $(\times 50$.) surface, allowing infectivity through high affinity CD4 interactions. ${ }^{27}$

\section{Microglia and CD4 expression}

CD4 normally has an important role in activating $\mathrm{T}$ lymphocytes by interacting with major histocompatibility complex class II (MHC-II) molecules on the surface of local macrophages during antigen presentation to $\mathrm{T}$ cells. ${ }^{28}$ During HIV-1 infection, the presence of CD4 is crucial for the efficient binding of virions to the plasma membrane. ${ }^{26}$

CD4 has been found to be highly expressed on Langerhans cells, ${ }^{29}$ U937 monocytic cells, ${ }^{30}$ mouse brain microglia ${ }^{31}$ and more recently on resting human retinal microglia. ${ }^{32}$ However, many studies have been unable to detect CD4 on human brain microglia ${ }^{33}$ or have observed only very low CD4 levels in situ on activated human brain microglia. ${ }^{34}$

In the present study, we were unable to detect CD4 immunoreactivity on human retinal sections. In contrast, cultured retinal microglia expressed detectable levels of CD4 and this may be related to activation of microglia in culture or isolation of microglia from the normal immunosuppressive retinal environment. ${ }^{32} 35$

\section{Microglia and $F c$ receptor $(F c R)$ expression}

In this study, we have shown that cultured retinal microglial cells expressed Fc $\gamma$ RI (CD64) and Fc $\gamma$ RIII (CD16). In situ microglial cells expressed Fc $\gamma$ RI (CD64) but not Fc $\gamma$ RII (CD32) or Fc $\gamma$ RIII (CD16) in normal retina. The presence of Fc $\gamma$ receptors-that is, Fc $\gamma$ RI (CD64), Fc $\gamma$ RII (CD32), and Fc $\gamma$ RIII (CDl6) on human microglia has been reported in brain tissues from patients with multiple sclerosis. ${ }^{36}$

Fc $\gamma \mathrm{R}$ expression primarily serves to trigger the lysis of extracellular antibody coated targets. ${ }^{37}$ However, some pathogens may exploit the process of $\mathrm{Fc} \gamma \mathrm{R}$ binding to facilitate penetration into Fc $\gamma \mathrm{R}$ expressing cells. ${ }^{38}$ Fc $\gamma$ RIII has been reported to be absent on U937 cells ${ }^{39}$ and in such cells, CD4 in addition to FC $\gamma \mathrm{I}$ and Fc $\gamma \mathrm{II}$ receptors has been demonstrated to be necessary for any infection via the antibody dependent enhancement (ADE) process. ${ }^{40}$ 

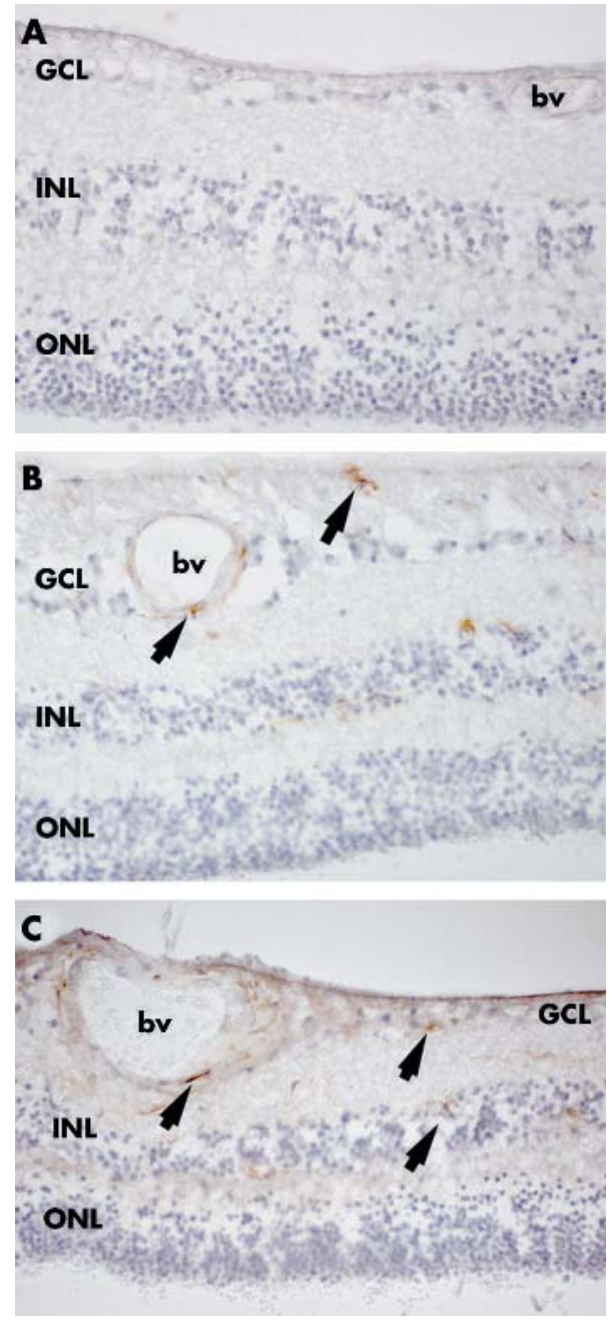

Figure 3 Immunoperoxidase staining of human retinal sections. (A) lgG non-specific isotype control $(\times 50)$; (B) vessel associated and parenchymal microglial cells immunolabelled with anti-CD45 antibody (arrows) ( $\times 50)$; (C) CD64 immunopositive vessel associated and parenchymal cells are seen in the inner retinal layers (arrows) $(\times 50)$. (GCL, ganglion cell layer; INL, inner nuclear layer; ONL, outer nuclear layer; bv, blood vessel)

Although infection with HIV-1 in monocytes/macrophages can occur via interaction of the viral envelope glycoprotein (gpl20) with the CD4 receptor, ${ }^{41}$ viral infection may also occur through the interaction of antibody opsonised HIV-1 with $\mathrm{Fc} \gamma$ receptors on monocytic cell types in an ADE process. ${ }^{42}$ The involvement of Fc $\gamma$ receptors in HIV membrane fusion remains to be defined. One study, for example, found that during infection via the Fc $\gamma R$ pathway, high affinity Fc $\gamma$ RI (CD64) as well as Fc $\gamma$ RIII (CDl6) may be critical for $\mathrm{ADE}$ to occur. ${ }^{25}$ In contrast, another study has shown that macrophages expressing all three Fc $\gamma$ receptors, only antibodies against Fc $\gamma$ RIII molecules (CD16) completely abolish viral penetration. ${ }^{43}$ HIV-1 infection of cells that do not express Fc $\gamma$ RIII appears to be dependent on the presence of gp120-CD4 binding. ${ }^{44}$

\section{Microglia and chemokine receptor expression}

Individuals homozygous to mutant alleles of CCR5 with a 32 bp deletion $(\Delta 32)$ have been shown to be resistant to HIV1 infection, indicating the importance of CC chemokine receptor CCR5 during HIV-1 infection. ${ }^{45}$ Recent studies have demonstrated that gpl20-chemokine receptor interaction occurs at the level of the third variable loop, more precisely next to the CD4 inducible epitopes on gp120. ${ }^{46}$ The presence of soluble CD4 and preservation of the third loop are critical for viral binding to CCR5.$^{47}$ Deletion of this loop preserves binding of CD4 to gp120 but ablates binding to CCR5, although the deletion of both first and second loops does not alter the binding of gp 120/CD4 complex to CCR5.$^{48}$ Moreover, the addition of gpl20 from macrophage but not $\mathrm{T}$ cell tropic isolates may inhibit the binding of chemokines to CD4 and CCR5 expressing cells. ${ }^{49}$ In situ, CD4 is more important for the interaction between viral envelope and the chemokine receptors and the addition of soluble CD4 can abolish HIV-I infection. ${ }^{48}$

The expression of chemokine receptors has not been reported previously on human retinal microglia. However, U937 monocytic cells and human brain microglia have been shown to express CCR5, the co-receptor most commonly used by viral isolates; these cells can be infected with many macrophage tropic HIV-l strains. ${ }^{50}$ Moreover, antibodies against CCR5 can inhibit microglial infection with HIV-1, while anti-CCR3 and anti-CXCR4 antibodies have little or no effect. $^{51}$

The present study shows that retinal microglia can express immunoreactivity for viral binding receptors and as such, may be involved in the pathogenesis of viral retinopathies including HIV-1/AIDS retinopathy.

\section{ACKNOWLEDGEMENTS}

Supported in part by an AusAID Postgraduate Scholarship (VTP), and Sydney Foundation for Medical Research (MCM).

\section{Authors' affiliations \\ V T Pham, L Wen, M C Madigan, P L Penfold, Save Sight Institute, University of Sydney, Australia \\ P McCluskey, Ophthalmology Department, Royal Prince Alfred Hospital, Sydney, Australia \\ Competing interests: None of the authors have any financial or commercial conflict of interest.}

\section{REFERENCES}

1 Barron KD. The microglial cell. A historical review. J Neurol Sci 1995; 134(Suppl):57-68

2 Stoll G, Jander S. The role of microglia and macrophages in the pathophysiology of the CNS. Prog Neurobiol 1999;58:233-47.

3 Penfold PL, Provis JM, Liew SC. Human retinal microglia express phenotypic characteristics in common with dendritic antigen-presenting cells. J Neuroimmunol 1993;45:183-91.

4 Matsubara T, Pararajasegaram G, Wu GS, et al. Retinal microglia differentially express phenotypic markers of antigen-presenting cells in vitro. Invest Ophthalmol Vis Sci 1999;40:3186-93.

5 Gelbard HA, Nottet HS, Swindells S, et al. Platelet-activating factor: a candidate human immunodeficiency virus type 1 -induced neurotoxin. J Virol 1994;68:4628-35.

6 Wesselingh SL, Takahashi K, Glass JD, et al. Cellular localization of tumor necrosis factor mRNA in neurological tissue from HIV-infected patients by combined reverse transcriptase/polymerase chain reaction in situ hybridization and immunohistochemistry. J Neuroimmunol 1997;74:1-8.

7 Prospero-Garcia O, Gold LH, Fox HS, et al. Microglia-passaged simian immunodeficiency virus induces neurophysiological abnormalities in monkeys. Proc Natl Acad Sci USA 1996;93:14158-63.

8 Moses AV, Bloom FE, Pauza CD, et al. Human immunodeficiency virus infection of human brain capillary endothelia cells occurs via a CD4/ galactosylceramide-independent mechanism. Proc Natl Acad Sci USA 1993;90:10474-78.

9 Nath A. Pathobiology of human immunodeficiency virus dementia. Semin Neurol 1999;19:113-27.

10 Brodie SE, Friedman AH. Retinal dysfunction as an initial ophthalmic sign in AIDS. Br J Ophthalmol 1990;74:49-51.

11 Geier SA, Held M, Bogner JR, et al. Impairment of tritan colour vision after initiation of treatment with zidovudine in patients with HIV disease or AIDS. Br J Ophthalmol 1993;77:315-6

12 McCluskey PJ. HIV-related eye disease. Med J Aust 1993;158:111-3.

13 Cantrill HL, Henry K, Sannerud K, et al. HIV infection of the retina. NEngl J Med 1988;318:1539.

14 Pomerantz RJ, Kuritzkes DR, de la Monte SM, et al. Infection of the retina by human immunodeficiency virus type I. N Engl J Med 1987;317:1643-7. 
15 Saadati HG, Khan IA, Lin XH, et al. Immunolocalization of IL-1 beta and IL-6 in optic nerves of patients with AIDS. Curr Eye Res 1999;19:264-8.

16 Kreutzberg GW. Microglia, the first line of defence in brain pathologies. Arzneimittelforschung 1995;45:357-60.

17 Kaul M. Lipton SA. Chemokines and activated macrophages in HIV gpl20induced neuronal apoptosis. Proc Natl Acad Sci USA 1999;96:8212-6.

18 Sadun AA, Pepose JS, Madigan MC, et al. AIDS-related optic neuropathy: a histological, virological and ultrastructural study. Graefes Arch Clin Exp Ophthalmol 1995;233:387-98.

19 Pepose JS, Holland GN, Nestor MS, et al. Acquired immune deficiency syndrome. Pathogenic mechanisms of ocular disease. Ophthalmology 1985;92:472-84.

20 Gariano RF, Rickman LS, Freeman WR. Ocular examination and diagnosis in patients with the acquired immunodeficiency syndrome. West J Med 1993; 158:254-62.

21 Rao NA, Zhang J, Ishimoto S. Role of retinal vascular endothelial cells in development of CMV retinitis. Trans Am Ophthalmol Soc 1998;96:111-23, discussion 124-6

22 Diaz CM, Penfold PL, Provis JM. Modulation of the resistance of a human endothelial cell line by human retinal glia. Aust NZ J Ophthalmol 1998;26Suppl 1:S62-4.

23 Collman RG, Yi Y. Cofactors for human immunodeficiency virus entry into primary macrophages. J Infect Dis 1999;179(Suppl 3):S422-6.

24 Jouault T, Chapuis F, Bahraoui E, et al. Infection of monocytic cells by HIV-1: combined role of FCR and CD4. Res Virol 1991;142:183-8.

25 Takeda A, Ennis FA. FcR-mediated enhancement of HIV-1 infection by antibody. AIDS Res Hum Retroviruses 1990;6:999-1004.

26 Stauber RH, Rulong S, Palm G, et al. Direct visualization of HIV-1 entry: mechanisms and role of cell surface receptors. Biochem Biophys Res Commun 1999;258:695-702.

27 Connor RI, Dinces NB, Howell AL, et al. Fc receptors for lgG (Fc $\gamma R s$ ) on human monocytes and macrophages are not infectivity receptors for human deficiency virus type I (HIV-1): studies using bispecific antibodies to target HIV 1 to various myeloid cell surface molecules, including FcgR. Proc Natl Acad Sci USA 1991:88:9593-97.

28 Geleziunas R, Morin N, Wainberg MA. Mechanisms of down-modulation of CD4 receptors on the surface of HIV-1 infected cells. Science de la vie 1996; 139:653-62.

29 Zoeteweii JP, Blauvelt A. HIV-Dendritic cell interactions promote efficient viral infection of T cells. J Biomed Sci 1998;5:253-9.

30 Teppler H, Lee SH, Rieber EP, et al. Murine immunoglobulin G anti-CD4 monoclonal antibodies bind to primary human monocytes and macrophages through Fc receptors as well as authentic CD4. AIDS 1990;4:627-32.

31 Slepko N, Levi G. Progressive activation of adult microglial cells in vitro. Glia 1996;16:241-6.

32 Broderick C, Duncan L, Taylor N, et al. IFN-gamma and LPS-mediated IL-10dependent suppression of retinal microglial activation. Invest Ophthalmol Vis Sci 2000;41:2613-22.

33 Vazeux R. AIDS encephalopathy and tropism of HIV for brain monocytes/ macrophages and microglial cells. Pathobiology 1991;59:214-8.

34 Dick A, Pell M, Brew B, et al. Direct ex vivo flow cytometric analysis of human microglial cells CD4 expression: examination of central nervous system biopsy specimens from HIV-seropositive patients and patients with other neurological disease. AIDS 1997;11:1699-708.

35 Dick $A D$, Carter $D$, Robertson $M$, et al. Control of myeloid activity during retinal inflammation. J Leukoc Biol 2003:74:161-6.

36 Ulvestad E, Williams K, Vedeler C, et al. Reactive microglia in multiple sclerosis lesions have an increased expression of receptors for the Fc part of lgG. J Neurol Sci 1994;121:125-31.

37 Fanger MW, Shen L, Graziano RF, et al. Cytotoxicity mediated by human Fc receptors for lgG. Immunol Today 1989;10:92-9.

38 Peiris JS, Porterfield JS. Antibody-mediated enhancement of flavivirus replication in macrophage-like cell lines. Nature 1979;282:509-11.

39 Takeda A, Sweet RW, Ennis FA. Two receptors are required for antibodydependent enhancement of human immunodeficiency virus type 1 infection: CD4 and Fc gamma R. J Virol 1990;64:5605-10.

40 Montefiori DC. Role of complement and Fc receptors in the pathogenesis of HIV-1 infection. Springer Semin Immunopathol 1997; 18:371-90.

41 Collman R, Godfrey B, Cutilli J, et al. Macrophage-tropic strains of human immunodeficiency virus type 1 utilize the CD4 receptor. J Virol 1990;64:4468-76.

42 Connor RI, Dinces NB, Howell AL, et al. Fc receptors for lgG (Fc gamma Rs) on human monocytes and macrophages are not infectivity receptors for human immunodeficiency virus type 1 (HIV-1): studies using bispecific antibodies to target HIV-1 to various myeloid cell surface molecules, including the Fc gamma R. Proc Natl Acad Sci USA 1991;88:9593-7.

43 Trischmann H, Davis D, Lachmann PJ. Lymphocytotropic strains of HIV type 1 when complexed with enhancing antibodies can infect macrophages via $\mathrm{Fc}$ gamma RIII, independently of CD4. AIDS Res Hum Retroviruses 1995; 11:343-52.

44 Perno CF, Baseler MW, Broder S, et al. Infection of monocytes by human immunodeficiency virus type 1 blocked by inhibitors of CD4-gp120 binding, even in the presence of enhancing antibodies. J Exp Med 1990;171:1043-56

45 Ghorpade A, Xia MQ, Hyman BT, et al. Role of the beta-chemokine receptors CCR3 and CCR5 in human immunodeficiency virus type 1 infection of monocytes and microglia. J Virol 1998;72:3351-61.

46 Wu L, Gerard NP, Wyatt R, et al. CD4-induced interaction of primary HIV-1 gp1 20 glycoproteins with the chemokine receptor CCR-5. [see comments] Nature, 1996;384:179-83.

47 Potz J, Basiripour L, Dorfman T, et al. The V3 domain of the HIV-1 gp1 20 envelope glycoprotein is critical for chemokine-mediated blockade of infection. [see comments] Science, 1987;237:1351-5.

48 Choe H, Martin KA, Farzan M, et al. Structural interactions between chemokine receptors, gp1 20 Env and CD4. Semin Immunol 1998;10:249-57.

49 Trkola A, Dragic T, Arthos J, et al. CD4-dependent, antibody-sensitive interactions between HIV-1 and its co-receptor CCR-5. [see comments] Nature, 1996:384:184-7

50 Zella D, Barabitskaja O, Burns JM, et al. Interferon-gamma increases expression of chemokine receptors CCR1, CCR3, and CCR5, but not CXCR4 in monocytoid U937 cells. Blood 1998;91:4444-50.

51 Albright AV, Shieh JT, Itoh T, et al. Microglia express CCR5, CXCR4, and CCR3, but of these, CCR5 is the principal coreceptor for human immunodeficiency virus type 1 dementia isolates. J Virol 1999;73:205-13. 